\title{
Review
}

\section{Granzymes in cancer and immunity}

\author{
SP Cullen ${ }^{1}$, M Brunet ${ }^{1}$ and SJ Martin ${ }^{\star, 1}$
}

Cytotoxic T lymphocytes (CTLs) and natural killer (NK) cells are indispensable factors in the body's ongoing defence against viral infection and tumor development. CTL/NK cells recognize and kill infected or abberant target cells by two major pathways: either through introduction of a battery of proteases - called granzymes - to the target cell cytosol, or through TNF superfamilydependent killing. During granzyme-dependent killing, target cell death is quick and efficient and is mediated by multiple granzymes, acting via redundant cell death pathways. Although granzyme-mediated cell death has been intensively studied, recent work has also hinted at an alternative, proinflammatory role for these enzymes. Thus, in addition to their well-established role as intracellular effectors of target cell death, recent data suggest that granzymes may have an extracellular role in the propagation of immune signals. In this study, we discuss the role of granzymes as central factors in antitumor immunity, as well possible roles for these proteases as instigators of inflammation.

Cell Death and Differentiation (2010) 17, 616-623; doi:10.1038/cdd.2009.206; published online 15 January 2010

Cytotoxic T cells (CTL) and natural killer (NK) cells recognize and kill virus-infected or transformed cells through two main pathways. CTLs use ligands of the tumor necrosis factor superfamily on their cell surface to bind and eliminate target cells expressing the corresponding receptors. ${ }^{1}$ In addition, CTL/NK cells also use the granule exocytosis pathway to target cell death, which operates through the delivery of the contents of cytotoxic granules to the surface of target cells. The granule protein, perforin, promotes granzyme delivery to the target cell cytosol and, on entry, these proteases cleave their cohort of substrates to promote rapid and efficient cell death. $^{2}$

Although there are multiple granzymes, each with distinctive cell death-promoting activity, evidence implicating individual granzymes with protection from tumor formation has been relatively scarce, as mice lacking individual granzymes typically remain cancer free. Because perforin facilitates the delivery of all granzymes to target cells, CTL/NK cells from perforin-deficient mice are defective in granzyme-mediated cytotoxicity. ${ }^{3,4}$ Importantly, perforin-knockout animals are much more susceptible to spontaneous tumor development than wild-type littermates and also succumb to chemically induced tumors at a higher rate, suggesting a redundancy of function between individual granzymes with regard to tumor control. ${ }^{3,5-7}$

Elevated levels of circulating extracellular granzymes $A$ and $B$ have previously been associated with various inflammatory diseases. ${ }^{8-10}$ Although this could simply reflect elevated CTL/ NK numbers in response to persistent inflammation - and associated spontaneous or inadvertent release of granzymes into the extracellular space - recent studies have suggested an alternative explanation for the presence of circulating granzymes. ${ }^{11-13}$ In what could well turn out to be a landmark paper on the subject, Metkar et al. ${ }^{12}$ have shown that extracellular granzyme A can promote the release of proinflammatory cytokines from human monocytic cells and murine peritoneal macrophages, the significance of which is underlined by the finding that granzyme A-deficient mice are resistant to the lethal effects of endotoxic shock. Coupled with observations that certain granzymes are expressed and secreted by B cells, mast cells, keratinocytes, basophils, as well as other cell types, in the absence of detectable perforin, this suggests that granzymes may have hitherto unsuspected roles in immunity. ${ }^{11,14-20}$ Thus, in addition to acting as cell death effector molecules on delivery to target cells, granzymes may also possess activity on release into the extracellular space (Figure 1). The expanding role for granzymes as possible soluble mediators of inflammation will be discussed later in this review.

\section{Cytotoxic Functions of Granzymes}

CTL/NK granzymes are typically safely contained within cytotoxic granules, in which they are prevented from damaging the host cell. After a CTL/NK cell recognizes a target, cytotoxic granules move along microtubules to polarize at the plasma membrane, adjacent to the target, where they are secreted into the immunological synapse between the two cells. ${ }^{2}$ The major constituents of cytotoxic granules are perforin and granzymes, which combine to promote rapid cell death when delivered to

\footnotetext{
${ }^{1}$ Department of Genetics, Molecular Cell Biology Laboratory, The Smurfit Institute, Trinity College, Dublin D2, Ireland

*Corresponding author: SJ Martin, Molecular Cell Biology Laboratory, Trinity College, Dublin, The Smurfit Institute of Genetics, Dublin D2, Ireland.

Tel: + 35318961 289; Fax: + 3531679 8558; E-mail: martinsj@tcd.ie

Keywords: apoptosis; cancer; granzymes; granzyme A; granzyme B; inflammation

Abbreviations: CTL, cytotoxic T lymphocyte; NK, natural killer; TNF, tumor necrosis factor; CAD, caspase-activated DNase; ICAD, inhibitor of caspase-activated DNase; RAG2, recombination-activating gene 2; MCA, Melamine Cyanurate; TCR, T cell receptor; TGF, transforming-growth factor; Treg, T regulatory; AICD, activationinduced cell death; IL, interleukin; MCMV, murine cytomegalovirus; HSP, heat-shock protein

Received 18.9.09; accepted 07.10.09; Edited by D Granville; published online 15.1.10
} 


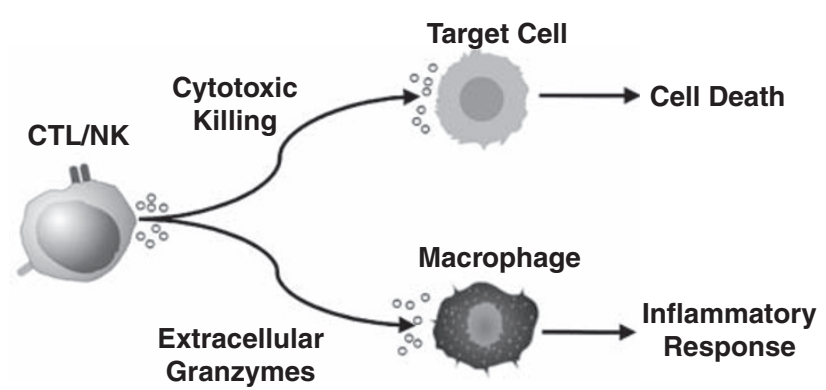

Figure 1 Cytotoxic versus inflammatory roles of granzymes. Although a large body of evidence implicates cytotoxic granule constituents in pathways resulting in target cell death, recent evidence suggests that these granzymes may also serve alternative functions as initiators or amplifiers of inflammatory responses. In the latter situation, granzymes released into the extracellular space may directly or indirectly provoke inflammatory reactions by acting on immune cells or through the actions of extracellular granzyme substrates on such cells

the target cell cytosol. The pore-forming protein, perforin, was originally thought to facilitate granzyme entry into target cells by physically forming holes in the cell membrane through which granzymes may pass. ${ }^{21}$ Although the intervening years have thrown up alternative mechanisms for perforin-mediated granzyme delivery, studies using knockout mice have unequivocally demonstrated the crucial role that this protein has in granzyme-mediated cytotoxicity. ${ }^{22,23}$ As effector cells lacking perforin cannot deliver granzymes to target cells, perforin deficiency translates into a complete loss of cytotoxic granzyme function, with perforin-deficient CTLs defective for target cell killing. ${ }^{22,23}$ As we shall discuss later, this leads to a plethora of immune deficiencies, which highlight the important role that the perforin/granzyme system has in defending the body against disease.

Granzymes are a distinct family of serine proteases, with different members harbored by humans and mice, likely reflecting the diverse environmental challenges met by their respective immune systems, which has led to different evolutionary trajectories of their constituent granzymes. Along with granzyme A, granzyme $B$ is one of the most abundant granzymes and, consequently, granzyme B-mediated cytotoxicity has been intensively studied. ${ }^{2,24,25}$ Effector cells lacking granzyme B kill targets at a much slower rate than do wild-type cells, which demonstrates the important role that this protease has in executing the timely demise of infected or tumorigenic cells. ${ }^{26,27}$ The efficiency of granzyme B-dependent killing is largely because of the ability of this protease to activate the target cell's intrinsic cell death proteases, the caspases, either directly or indirectly (Figure 2). Direct proteolysis and activation of caspases 3 and -7 by granzyme $B$ leads to the caspasemediated degradation of hundreds of cellular protein substrates, which promotes fast and efficient apoptosis., 28-30

In addition, granzyme B can also promote caspase activation through the well-defined cytochrome c/Apaf-1 pathway in which proteolysis and activation of the BH3-only protein BID by granzyme B promotes BID-mediated opening of the BAX/BAK channel in the mitochondrial outer membrane (Figure 2). This important event leads to BAX/BAK-mediated release of cytochrome $c$ from the mitochondrial intermembrane space into the cytosol, where it binds to and activates a caspase-activating platform, called the apoptosome.

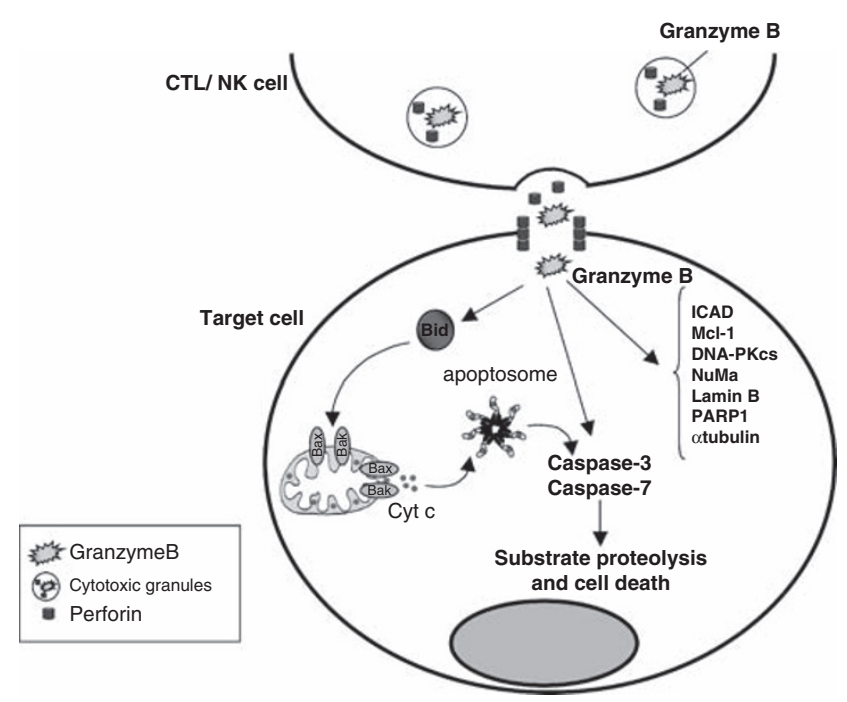

Figure 2 Pathways to granzyme B-mediated cell death. Granzyme B, together with other granzymes, enters the target cell by a perforin-dependent mechanism. On entry into the target cell cytosol, granzyme B promotes apoptosis through two main pathways, either through BID-dependent mitochondrial permeabilization or through direct caspase processing and activation. Granzyme B-mediated proteolysis of the $\mathrm{BH} 3$-only protein $\mathrm{BID}$ exposes a myristolyation signal in this protein, targeting it to mitochondria, in which it induces oligomerization of BAX and/ or BAK in the mitochondrial outer membrane. The latter event facilitates cytochrome $c$ release into the cytosol, assembly of the apoptosome, with subsequent caspase- 9 activation and the ensuing caspase cascade. Note that antiapoptotic BCL-2 family members can inhibit cytochrome $c$ release and block this pathway. Granzyme B can also directly process effector caspases 3 and -7 to promote apoptosis. Direct activation of the latter effector caspases leads to a caspase activation cascade and proteolysis of numerous caspase substrates, resulting in the efficient death of the target cell. Granzyme B can also directly cleave ICAD, the inhibitor of a DNase (CAD), which can promote internucleosomal DNA hydrolysis that is synonymous with this mode of killing. Granzyme B has also been shown to cleave a variety of other proteins implicated in the maintenance of nuclear integrity (Lamin B), as well as in protection against cell death (MCL-1), DNA repair (DNA-PK $\mathrm{cs}_{\mathrm{c}}$ ), microtubule dynamics ( $\alpha$-tubulin) and a host of autoantigens (NuMa, Mi-2)

In turn, the apoptosome promotes downstream caspase activation and cell death. ${ }^{31-33}$ Interestingly, human and mouse granzyme B show stark differences in their ability to access the BID pathway to cell death, with mouse granzyme B displaying little ability to process and activate BID as compared with its human counterpart. ${ }^{29,34,35}$ Importantly, on experimental inactivation of caspases, granzyme B can still kill cells - although with much slower kinetics - and this most likely results from BID-mediated mitochondrial dysfunction, together with proteolysis of other substrates by granzyme B, such as ICAD and $\beta$-tubulin (Figure 2). ${ }^{28,29,36}$

As mentioned above, effector cells lacking granzyme B retain cytotoxic activity through the actions of the remaining granzymes, of which granzyme $A$ is the most abundant. Whereas granzyme A may promote target cell death through multiple pathways, proteolysis of components of the endoplasmic reticulum-associated SET complex has been proposed to constitute the main mechanism for cell death by this granzyme (Figure 3). ${ }^{37}$ Activation of the Dnase NM23-H1 within this complex, by proteolysis and inactivation of its inhibitor (SET) by granzyme A, is thought to promote the single-strand DNA degradation most commonly associated with killing by this granzyme. ${ }^{37}$ In addition, proteolysis and 


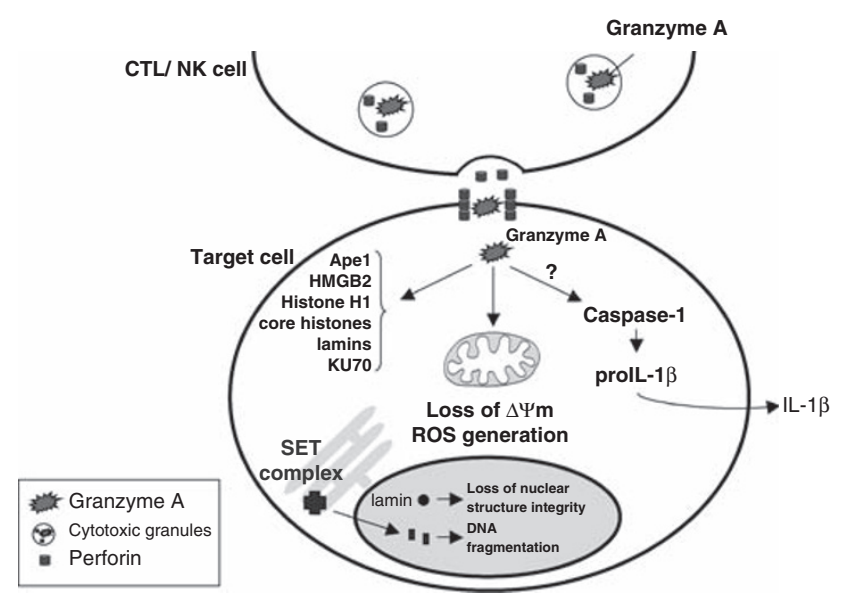

Figure 3 Granzyme A promotes cell death by targeting the nucleus and also mediates the release of mature IL-1 $\beta$. On entry into the target cell, granzyme A promotes a decrease in mitochondrial transmembrane potential (delta $\psi_{\mathrm{m}}$ ) and an increase in reactive oxygen species (ROS) through a poorly understood mechanism that might involve proteolysis of NDUFS3. This ROS increase leads to the translocation of the SET complex to the nucleus where it may be involved in the transcription of genes associated with oxidative stress responses. Granzyme A also directly targets three members of the SET complex for proteolysis: the nucleosome assembly protein, SET, the high mobility group protein 2 (HMG2) and the baseexcision repair enzyme apurinic/apyrimidinic endonuclease 1 (Ape 1). Proteolysis of SET releases the inhibition of DNase NM23-HI, resulting in the single-strand DNA nicks most commonly associated with granzyme A-mediated cell death. Granzyme $A$ also weakens the structural integrity of the nucleus by targeting Lamins $A-C$ for proteolysis. A recent study suggests that granzyme $A$ may also promote the release of the proinflammatory cytokine IL- $1 \beta$ through a mechanism dependent on caspase1-mediated proteolysis of pro-IL-1 $\beta$

activation of the $3^{\prime}-5^{\prime}$ endonuclease, TREX 1 , by granzyme $A$, may inhibit DNA repair by removing bases from the free $3^{\prime}$ ends, thus preventing NM23-H1-cut strands from re-annealing. ${ }^{38}$ Other pathways to granzyme A-mediated cell death have been described; however, recent work has questioned whether granzyme $\mathrm{A}$ has a cytotoxic role at physiological concentrations. This will be discussed later in the review when we consider possible non-cell death functions of this granzyme. ${ }^{12,35,39}$

The remaining granzymes have not been studied as comprehensively as granzyme A and B. However, recent work has begun to uncover a possible mode of action for some of these proteases. Similar to granzyme A, granzyme K shows tryptase-like activity and has been shown to process similar substrates. ${ }^{40-42}$ Thus, it is possible that granzyme $\mathrm{K}$ may be important in situations in which granzyme $A$ function has been compromised by viral inhibitors. Evidence of a role for granzyme $\mathrm{C}$ in promoting cell death is scant, although it may be cytotoxic in some contexts. ${ }^{43,44}$ The Metase, granzyme M, has been shown to promote a caspase- and mitochondriaindependent mechanism of cell death. ${ }^{45}$ More recently, it was suggested that this granzyme may promote cell injury by disrupting the microtubule network through proteolysis of $\alpha$-tubulin and also by cleavage and inactivation of the essential multifunctional protein, nucleophosmin. ${ }^{46,47}$

One of the persistent problems associated with studies relating to the cytotoxic activity of various granzymes is whether the concentrations of granzymes that have been used to demonstrate cytotoxicity are actually achievable under physiological settings. Whereas granzyme B displays cytotoxic activity at low nanomolar concentrations, many studies in this area have used granzymes at micromolar concentrations that may not be attainable in vivo. Because the concentration of granzymes that are delivered at the immunological synapse is unknown, it remains to be determined whether all granzymes are truly cytotoxic at physiological levels or have other roles in CTK/NKmediated processes.

\section{Role of the Immune System in Cancer Prevention}

Immune surveillance describes the process whereby precancerous and malignant cells are recognized by the immune system as damaged and are consequently targeted for elimination. In recent years, this model has been broadened to include the concept of immunoediting, in which transformed cells evolve under selective pressure from the immune system to give rise to tumors that are increasingly immune resistant. ${ }^{48}$ However, although some tumors undoubtedly escape clearance in this way, evidence is mounting to suggest that cells of the immune system can prevent the growth of precancerous cells and also mediate regression of established tumors. ${ }^{16}$ In early studies on this subject, the rate of spontaneous solid tumor formation in nude mice, which lack a thymus and therefore possess a greatly reduced number of $T$ cells, was found to be the same as that of their wild-type littermates. ${ }^{49,50}$ Although the growth of experimentally induced tumors was somewhat higher in these mice, the results cast doubt on the ability of the immune system to protect against tumor growth. ${ }^{51}$ However, it was subsequently discovered that nude mice possess NK cells and a limited number of functional CTLs. More convincing evidence for tumor immune surveillance came from the observation that mice lacking RAG2, which is required for T-cell receptor gene rearrangement (such mice thus lack mature B or T cells), are much more susceptible to spontaneous tumor formation and also develop tumors at a greater rate on exposure to carcinogens or after injection of tumor cells. ${ }^{52}$ Specifically, $60 \%$ of RAG2 $^{-l-}$ mice developed tumors after treatment with the chemical carcinogen, MCA, whereas only $13 \%$ of wildtype mice developed MCA-induced tumors. In addition, all RAG2 ${ }^{-1-}$ mice spontaneously formed malignant lesions, half of which developed into carcinomas, whereas $81 \%$ of wildtype mice remained cancer free. ${ }^{52}$ This study has since been reinforced by others that used mice deficient in different components of the TCR system to examine the important contribution of specific T-cell subsets to cancer prevention. ${ }^{53}$ In addition, the importance of NK cells for cancer immunity has been illustrated by studies in which mice with gene-targeted or depleted NK and NKT cell populations were found to be 2-3 times more likely to develop MCA-induced tumors. ${ }^{54,55}$ Therefore, aside from the eradication of cells infected with transforming viruses, CTL/NK cells have an important role in preventing the initiation and progression of cancer.

\section{The Perforin-Granzyme Pathway in Cancer Prevention}

Although both granzymes $A$ and $B$ have been shown to be important for clearing viruses such as ectromelia, an 
increased risk of cancer has yet to be conclusively associated with the loss of individual granzymes ${ }^{56-61}$. Nevertheless, perforin-deficient mice are much more likely to develop tumors in a number of different settings, which highlights the significant redundancy of function that exists among granzymes with regard to tumor eradication. ${ }^{3,5-7}$

As mentioned above, loss of perforin leads to a complete failure of effector cells to lyse targets in vitro. ${ }^{3}$ In addition to a failure to clear lymphocytic choriomeningitis virus, perforindeficient mice were initially observed to be partially defective in eradicating experimentally introduced fibrosarcoma tumor cells. ${ }^{3}$ In a follow-up study, perforin-deficient mice developed fibrosarcomas - initiated by treatment with the carcinogen MCA - much more rapidly and with greater incidence than did wild-type mice, whereas sarcomas induced by the Maloney murine sarcoma virus were larger and less likely to regress. ${ }^{7}$ NK cells were subsequently shown to mediate antitumor cytotoxicity in a perforin-dependent manner, which suggests that perforin/granzymes have a role in the innate immune response to tumors. ${ }^{5,62,63}$

With regard to spontaneous tumor formation, perforindeficient mice were found to be at a much greater risk of developing malignancy in certain B, T and NKT cells. Indeed, over half of all perforin-deficient animals developed spontaneous B-cell lymphomas after 12 months of age. ${ }^{55}$ The role of perforin in protecting against lymphoma was underlined by the finding that the combined loss of perforin and p53 resulted in earlier onset but not increased incidence of lymphoma when compared with perforin knockout alone, suggesting that perforin, rather than $\mathrm{p53}$, is the main factor in lymphoma surveillance. ${ }^{55}$ Significantly, tumor rejection was mediated by NK cells or $\gamma-\delta$ T cells in a perforin-dependent manner when lymphomas from perforin-null mice were transplanted into their wild-type littermates. ${ }^{6}$ Therefore, the perforin/granzyme system seems to have an important role in lymphoma prevention, at least in some settings.

Tumor progression requires suitable growth-promoting conditions in the area surrounding the developing tumor and, as most cancer patients possess viable immune cells, a critical aspect of cancer progression entails inhibition or evasion of the immune system. ${ }^{64}$ In normal cells, TGF- $\beta$ blocks progression of the cell cycle to stop proliferation, promote differentiation or induce apoptosis. However, many cancer cells acquire resistance to the antiproliferative effects of TGF- $\beta$, which greatly aids cancer progression. In addition, tumors can escape from immune surveillance by secreting immunosuppressive TGF- $\beta$, which inhibits proliferation and activation of $\mathrm{T}$ cells in the tumor microenvironment, making TGF- $\beta$ production one of the most potent mechanisms of immune avoidance by tumors. ${ }^{65}$ It is therefore significant that an important mechanism through which TGF- $\beta$ inhibits T-cell mediated tumor clearance is by the inhibition of the expression of five cytotoxic genes including perforin, granzyme $A$ and granzyme B. ${ }^{66}$ Importantly, inhibition of TGF- $\beta$ in mice restored cytolytic gene expression in CTLs and promoted tumor clearance, further emphasizing the role of the perforin/ granzyme pathway in tumor prevention. ${ }^{66}$

Regulatory $\mathrm{T}$ cells normally promote tolerance to selfantigens by eliminating self-reactive lymphocytes. ${ }^{67}$ Unfortunately, Treg cells have also been shown to induce tolerance to tumor-associated antigens, thus inhibiting the T cell-mediated antitumor immune response. ${ }^{67}$ Interestingly, CD4 ${ }^{+}$Foxp $^{+}$ Treg-mediated inactivation of tumor-specific CTLs in the tumor microenvironment has been shown to be contact dependent and reliant on perforin and granzyme $B$ to the extent that mice lacking this granzyme clear transplanted tumor cell lines more efficiently than do wild-type mice. ${ }^{68}$ Therefore, in some settings, a tumor may turn the tables on the immune system by using the destructive power of the perforin/granzyme pathway to its advantage. However, more evidence is required before this concept can be fully embraced. ${ }^{68}$

\section{A Role for Granzymes in Immunomodulation}

Although the perforin/granzyme pathway has an important role in CTL-mediated clearance of tumorigenic and infected cells, it may also have a role in regulating immune system homeostasis during infection. In humans, loss of perforin function leads to a syndrome called familial hemophagocytic lymphohistiocytosis, caused by the inability of activated CTLs to efficiently clear antigen-presenting targets. ${ }^{69}$ This has dire consequences for immune system function, as both $T$ cells and macrophages expand to meet a persistent pathogen challenge, leading to harmful levels of proinflammatory cytokines in circulation. In addition, overactivated macrophages phagocytose blood cells, leading to severe anemia. ${ }^{69}$

Although failure to clear certain viruses can lead to deregulated immune system homeostasis, evidence is emerging to suggest that granzymes may also be involved in the elimination of clonally expanded CD4 ${ }^{+} \mathrm{T}$ cells, which is required to control the size of the lymphocyte pool during and after infection. One of the major mechanisms of CD4 ${ }^{+}$T-cell eradication is by activation-induced cell death (AICD), which is normally mediated through the Fas-Fas ligand death pathway. However, granzymes have recently been found to promote AICD in patients with nonfunctioning Fas. Autoimmune lymphoproliferative syndrome is caused by a loss of function mutation in the CD95/FAS gene, leading to lymphoproliferation and autoimmunity, presumably through a failure of $\mathrm{T}$ cells to undergo AICD. Interesting recent evidence suggests that the perforin/granzyme pathway can promote AICD of T lymphocytes purified from these patients. However, the extent to which this can compensate for loss of the Fas pathway has not been determined. ${ }^{70,71}$ Intriguingly, activated $B$ cells have also been found to express and secrete granzyme $\mathrm{B}$, leading to the possibility that this granzyme may participate in $B$ cell-dependent immune responses. However, the role that granzyme $B$ has in this context remains unclear. ${ }^{11,15}$

\section{Extracellular Role of Granzymes in Immune Reactions}

Since their discovery over 20 years ago, granzymes have been largely understood to function in an intracellular context, promoting the death of virus-infected or transformed cells by proteolysis of substrates (such as BID and caspases) within such cells. Apart from sporadic reports proposing other roles for these proteases, the vast majority of granzyme research has focused on elucidating the cell death-inducing properties 
of these enzymes (Figure 1). However, recent work has uncovered a novel, noncytotoxic role for granzymes in the propagation of immune signals, which may open the door for a new area of granzyme research.

Granzyme A. It has long been known that patients presenting with infectious disease and certain proinflammatory conditions have elevated levels of granzyme A in the extracellular space. For example, rheumatoid arthritis patients have increased levels of granzyme A in the synovial fluid of swollen joints. ${ }^{72}$ In addition, high levels of this protease have been noted in the bronchoalveolar lavage of asthma sufferers and in patients with chronic obstructive pulmonary disease. ${ }^{73,74}$ The idea that high levels of circulating granzyme $A$ are associated with overactivation of the immune system is also borne out by studies that have identified increased levels of this protease in patients with persistent HIV infection or acute cytomegalovirus and Epstein-Barr virus infection, and this could reflect increased CTL/NK activity and impaired clearance of dead cytotoxic cells. ${ }^{26,75,76}$ Extracellular substrates for granzyme A are only beginning to emerge (Table 1); however, it is possible that proteolysis of cell surface proteins by circulating granzyme A may mediate some of the damage seen in proinflammatory disease states associated with this enzyme. ${ }^{77}$

Although granzyme A was observed to promote cytokine release from monocytes and to cleave and possibly activate the proinflammtory cytokine IL-1 $\beta$ over 20 years ago, a causal link between high levels of circulating granzyme $A$ and the propagation of proinflammatory conditions was not fully appreciated until recently. ${ }^{78,79}$ In addition to the previously described role in monocyte activation, Metkar et al. ${ }^{12}$ have shown that granzyme $A$, whether purified or supplied by $\mathrm{CTL}$, can promote the release of $\mathrm{IL}-1 \beta$ from primary mouse macrophages. Importantly, granzyme A-null mice are protected from the lethal effects of LPS-induced toxicity, which supports a role for this granzyme in proinflammatory cytokine signaling during infection. ${ }^{12}$ The role of the inflam- mation-associated protease, caspase-1, in promoting the maturation of IL- $1 \beta$ during infection has long been known. ${ }^{80,81}$ Granzyme A-mediated release of IL-1 $\beta$ from macrophages seems to be dependent on caspase-1 activity, which suggests a mechanism whereby granzyme $A$ can alert the immune system to disease by tapping into this important cell intrinsic proinflammatory pathway. ${ }^{12}$ Together with recent data indicating that native granzyme A may not be cytotoxic at physiological concentrations, this work suggests that the primary role of granzyme $A$ in the response of the immune system to infection and disease is only beginning to emerge. ${ }^{12,35}$ Indeed, the recent observation that granzyme A may contribute to the lethal hypersecretion of $\mathrm{TNF} \alpha$ during MCMV infection of perforin-null mice supports the notion of this granzyme as a mediator of immune signaling. ${ }^{82}$

Granzyme B. In addition to granzyme A, high levels of circulating extracellular granzyme $B$ have also been observed in patients presenting with various infections and disease states, the most well documented being rheumatoid arthritis. ${ }^{8-10,76}$ Granzyme B has been shown to cleave many extracellular matrix components including fibronectin, vitronectin and laminin (Table 1), which may promote detachment-induced cell death, or anoikis. ${ }^{83,84}$ Indeed, targeting of the extracellular matrix has been proposed as a mechanism of granzyme B-mediated joint erosion during rheumatoid arthritis, which may explain the proinflammatory activites of this granzyme in some contexts. ${ }^{9}$ However, the observation that granzyme $B$ knockout mice are even more resistant to the lethal effects of LPS-induced endotoxic shock than mice deficient in granzyme A suggests that granzyme B may have a more central, noncytotoxic role in the immune response to disease than previously appreciated. $^{12}$ Indeed, ECM proteins such as hyaluronan may also act as danger signals on proteolysis by extracellular proteases and, in this form, may function to promote immune cell activation. ${ }^{85-87}$

Table 1 Extracellular granzyme substrates

\begin{tabular}{|c|c|c|c|}
\hline Granzyme & $\begin{array}{l}\text { Enzymatic } \\
\text { activity }\end{array}$ & Substrates & Proposed functions \\
\hline A & Tryptase & $\begin{array}{l}\text { Pro-urokinase plasminogen } \\
\text { activator }^{96} \\
\text { Fibronectin }^{77} \\
\text { Collagen } \mathrm{IV}^{77} \\
\text { Myelin basic protein } \\
\text { Basement membrane proteoglycans } \\
\text { Th8 } \\
\text { Thrombin-like receptor or neurites } \\
\text { Platelet thrombin receptor } \\
\text { Proteinase-activated receptor } 2^{100}\end{array}$ & $\begin{array}{l}\text { Lymphocyte migration. } \\
\text { Fibrin clots. } \\
\text { Lymphocyte migration. } \\
\text { Lymphocyte migration. } \\
\text { Pathogenesis of multiple sclerosis. } \\
\text { Monocyte activation, cytokine production by fibroblasts and epithelial cells. } \\
\text { Induction of neurite retraction. } \\
\text { Desensitization of platelets to thrombin-induced aggregation. } \\
\text { Infectious colitis pathogenesis }\end{array}$ \\
\hline$B$ & Aspase & $\begin{array}{l}\text { Aggrecan, cartilage proteoglycans }{ }^{101} \\
\text { Vitronectin, fibronectin and laminin }^{83} \\
\text { Fibronectin, smooth muscle cells } \\
\text { ECM }^{102} \\
\text { Neuronal glutamate receptor }^{103} \\
\text { Plasminogen }\end{array}$ & $\begin{array}{l}\text { Joint destruction in rheumatoid arthritis. } \\
\text { Extracellular matrix remodeling, induction of anoikis of endothelial cells. } \\
\text { Possibly lymphocyte migration. Limitation of virus infectivity. Inhibition of } \\
\text { tumour cell migration. } \\
\text { Perforin-independent death (atherosclerosis). } \\
\text { Autoantigens generation in Rasmussen's encephalitis. } \\
\text { Vascular defects (scleroderma) }\end{array}$ \\
\hline $\mathrm{K}$ & Tryptase & Unknown & $\begin{array}{l}\text { Substrates and function are unknown but elevated levels are detected in } \\
\text { sepsis and human lung diseases }{ }^{73,88}\end{array}$ \\
\hline
\end{tabular}


Other granzymes. Elevated levels of granzyme $\mathrm{K}$ have been found in plasma from septic patients while this granzyme was also upregulated in acute airway inflammation, suggesting that other granzymes may also have proinflammatory roles. In addition, both granzyme $\mathrm{H}$ and granzyme $\mathrm{B}$ have been shown to limit viral replication by directly targeting viral proteins for proteolytic degradation, which suggests a noncytotoxic role for granzymes in protecting against infection. ${ }^{88-91}$

Thus, a new paradigm for granzyme action is beginning to emerge in which granzymes released or actively secreted into the extracellular space may promote cytokine activation/ secretion, either directly or indirectly, thereby amplifying immune responses to infected or transformed cells (Figure 1).

\section{How are Granzymes Released During Inflammation?}

Although the requirement of perforin for granzyme delivery to target cells has been well described, little is known about how granzymes may escape into the extracellular space to promote inflammation. One obvious mechanism of granzyme release is through the leakage of these proteases from the immunological synapse during CTL/NK killing, although a possible escape of granzymes in this way has not been rigorously investigated. However, it is also possible that granzymes may be actively released into the extracellular space under certain circumstances, and their actions may be completely perforin independent in this context.

In this regard, it is noteworthy that several groups have independently reported that non-CTL/NK cells express granzymes in response to stimuli that activate such cells. For example, transformed and activated primary B cells, mast cells, keratinocytes, basophils, macrophages and blood polymorphonuclear neutrophils have all been shown to express granzyme B. ${ }^{11,14-20}$ Mast cells are especially abundant at the boundary between the internal environment and the outside world, for example, in the skin and lungs, and are thus perfectly situated to coordinate an immune response against a nascent infection. Granzyme B, but not granzyme A or perforin, is expressed by mast cells and secreted in an active form after ligation of the Fc $\varepsilon$ R 1 receptor. ${ }^{17}$ Basophilsecreted granzyme B promoted the death of adherent target cells and degraded endothelial cell-cell contacts and this has been suggested to mediate increased vascular permeability and extravasation by basophils at points of infection. ${ }^{17}$ Furthermore, keratinocytes have been shown to express granzyme B and perforin on irradiation, with UVB-treated keratinocytes acquiring cytotoxicity toward various transformed cell lines in a perforin/granzyme B-dependent manner. ${ }^{92}$ Recently, primary $B$ cells were found to secrete active granzyme $B$, but not perforin or granzyme $A$, in the presence of IL-21 after B-cell receptor stimulation with either viral antigens or activating antibodies. ${ }^{11} \mathrm{~B}$ cells from patients previously vaccinated against certain viruses produced more granzyme B when subsequently challenged with specific viral antigen, whereas granzyme B-expressing B cells lived longer and were more active than nongranzyme B-expressing memory B cells. ${ }^{11} \mathrm{~B}$ cell-secreted granzyme B may therefore augment the immune response to a nascent infection and may account for elevated granzyme B levels in serum from virusinfected patients. ${ }^{76}$ Thus, evidence is accumulating to indicate that CTL/NK cells are not the only cells capable of producing and releasing active granzyme $\mathrm{B}$.

Danger signals, or alarmins, are endogenous molecules that normally reside within cells but are released into the extracellular milieu during necrosis, generally as a result of trauma-induced cell lysis. Release of these proteins is followed by binding to and activation of immune cells, which is thought to alert the immune system to potentially harmful situations. ${ }^{93}$ A large body of evidence implicates heat-shock protein 70 (HSP70) as a potential danger signal and it is interesting to note that HSP70 has been shown to mediate the uptake of granzyme $B$ in a perforin-independent manner. ${ }^{94}$ It is therefore intriguing to speculate that high levels circulating HSP70, released during situations of nonphysiological cell death such as chronic viral infection, may mediate the uptake of serum granzyme B by cells of the immune system and thus propagate the emerging proinflammatory properties of this protease. However, it is clear that investigations into the uptake of granzymes in noncytotoxic scenarios will require many more studies before a clearer picture begins to emerge.

\section{Conclusions}

The importance of the perforin/granzyme pathway in the prevention of cancer, as well as in immune homeostasis, has been clearly demonstrated by studies that use mice deficient in the crucial granzyme delivery agent, perforin. In addition, the recent study by Metkar et al. ${ }^{12}$, which demonstrated a profound resistance to LPS-induced shock in both granzyme A and granzyme B-deficient mice, has hinted at a new mode of action of these important proteases as effectors of inflammation. Apoptosis is characterized by the removal of unwanted cells from the body without giving rise to unnecessary immune responses, making this form of cell death immunologically silent. A recent study has identified a role for apoptosisinducing caspases as repressors of immune system activation through proteolysis and inactivation of the proinflammatory cytokine, IL-33. ${ }^{95}$ Thus, it is intriguing to speculate that, whereas caspases and granzymes were once considered to have equivalent functions in promoting cell death, their actions may diverge with regard to immune system activation, and this may ultimately reflect the different scenarios (physiological for caspases, disease-associated for granzymes) in which these enzymes become activated.

Going forward, the challenge will be to identify extracellular substrates for granzymes that on proteolysis, can explain the apparent proinflammatory effects of these proteases. Identification of such substrates may open up new perspectives on the underlying causes of persistent inflammation in chronic inflammatory conditions.

\section{Conflict of interest}

The authors declare no conflict of interest.

Acknowledgements. Work in the Martin laboratory is supported by SRC and $\mathrm{PI}$ grants from Science Foundation Ireland (SRCG20336 and 08/IN.1/B2031) and by The Wellcome Trust UK (082749). MB was supported by a fellowship from 
Fondation Recherché Medicale. SJM is a Science Foundation Ireland Principal Investigator.

1. Nagata $Y$, Ono S, Matsuo M, Gnjatic S, Valmori D, Ritter G et al. Differential presentation of a soluble exogenous tumor antigen, NY-ESO-1, by distinct human dendritic cell populations. Proc Natl Acad Sci USA 2002; 99: 10629-10634.

2. Cullen SP, Martin SJ. Mechanisms of granule-dependent killing. Cell Death Differ 2008; 15: 251-262.

3. Kagi D, Ledermann B, Burki K, Seiler P, Odermatt B, Olsen KJ et al. Cytotoxicity mediated by $T$ cells and natural killer cells is greatly impaired in perforin-deficient mice. Nature 1994; 369: 31-37.

4. Lowin B, Beermann F, Schmidt A, Tschopp J. A null mutation in the perforin gene impairs cytolytic T lymphocyte- and natural killer cell-mediated cytotoxicity. Proc Natl Acad Sci USA 1994; 91: 11571-11575.

5. Smyth MJ, Thia KY, Cretney E, Kelly JM, Snook MB, Forbes CA et al. Perforin is a major contributor to NK cell control of tumor metastasis. J Immunol 1999; 162: 6658-6662.

6. Street SE, Hayakawa Y, Zhan Y, Lew AM, MacGregor D, Jamieson AM et al. Innate immune surveillance of spontaneous $B$ cell lymphomas by natural killer cells and gammadelta T cells. J Exp Med 2004; 199: 879-884

7. van den Broek ME, Kagi D, Ossendorp F, Toes R, Vamvakas S, Lutz WK et al Decreased tumor surveillance in perforin-deficient mice. J Exp Med 1996; 184: 1781-1790.

8. Goldbach-Mansky R, Suson S, Wesley R, Hack CE, El-Gabalawy HS, Tak PP. Raised granzyme $B$ levels are associated with erosions in patients with early rheumatoid factor positive rheumatoid arthritis. Ann Rheum Dis 2005; 64: 715-721.

9. Ronday HK, van der Laan WH, Tak PP, de Roos JA, Bank RA, TeKoppele JM et al. Human granzyme $B$ mediates cartilage proteoglycan degradation and is expressed at the invasive front of the synovium in rheumatoid arthritis. Rheumatology (Oxford) 2001; 40 : $55-61$.

10. Tak PP, Kummer JA, Hack CE, Daha MR, Smeets TJ, Erkelens GW et al. Granzymepositive cytotoxic cells are specifically increased in early rheumatoid synovial tissue. Arthritis Rheum 1994; 37: 1735-1743.

11. Hagn M, Schwesinger E, Ebel V, Sontheimer K, Maier J, Beyer T et al. Human B cells secrete granzyme $B$ when recognizing viral antigens in the context of the acute phase cytokine IL-21. J Immunol 2009; 183: 1838-1845.

12. Metkar SS, Menaa C, Pardo J, Wang B, Wallich R, Freudenberg M et al. Human and mouse granzyme $A$ induce a proinflammatory cytokine response. Immunity 2008; 29 : 720-733.

13. Prakash MD, Bird CH, Bird PI. Active and zymogen forms of granzyme $B$ are constitutively released from cytotoxic lymphocytes in the absence of target cell engagement. Immuno Cell Biol 2009; 87: 249-254.

14. Berthou C, Michel L, Soulie A, Jean-Louis F, Flageul B, Dubertret L et al. Acquisition of granzyme $B$ and Fas ligand proteins by human keratinocytes contributes to epidermal cell defense. J Immunol 1997; 159: 5293-5300.

15. Jahrsdorfer B, Blackwell SE, Wooldridge JE, Huang J, Andreski MW, Jacobus LS et al. $B$-chronic lymphocytic leukemia cells and other $B$ cells can produce granzyme $B$ and gain cytotoxic potential after interleukin-21-based activation. Blood 2006; 108: 2712-2719.

16. Kim WJ, Kim H, Suk K, Lee WH. Macrophages express granzyme B in the lesion areas of atherosclerosis and rheumatoid arthritis. Immunol Lett 2007; 111: 57-65.

17. Pardo J, Wallich R, Ebnet K, Iden S, Zentgraf $\mathrm{H}$, Martin $\mathrm{P}$ et al. Granzyme B is expressed in mouse mast cells in vivo and in vitro and causes delayed cell death independent of perforin. Cell Death Differ 2007; 14: 1768-1779.

18. Strik MC, de Koning PJ, Kleijmeer MJ, Bladergroen BA, Wolbink AM, Griffith JM et al. Human mast cells produce and release the cytotoxic lymphocyte associated protease granzyme B upon activation. Mol Immunol 2007; 44: 3462-3472.

19. Tschopp CM, Spiegl N, Didichenko S, Lutmann W, Julius P, Virchow JC et al. Granzyme $B$, a novel mediator of allergic inflammation: its induction and release in blood basophils and human asthma. Blood 2006; 108: 2290-2299.

20. Wagner C, Stegmaier S, Hansch GM. Expression of granzyme B in peripheral blood polymorphonuclear neutrophils (PMN), myeloid cell lines and in PMN derived from haemotopoietic stem cells in vitro. Mol Immunol 2008; 45: 1761-1766.

21. Tschopp J, Masson D, Stanley KK. Structural/functional similarity between proteins involved in complement- and cytotoxic T-lymphocyte-mediated cytolysis. Nature 1986; 322: 831-834.

22. Bolitho P, Voskoboinik I, Trapani JA, Smyth MJ. Apoptosis induced by the lymphocyte effector molecule perforin. Curr Opin Immunol 2007; 19: 339-347.

23. Voskoboinik I, Trapani JA. Addressing the mysteries of perforin function. Immunol Cell Biol 2006; 84: 66-71.

24. Russell JH, Ley TJ. Lymphocyte-mediated cytotoxicity. Annu Rev Immunol 2002; 20: 323-370.

25. Trapani JA, Sutton VR. Granzyme B: pro-apoptotic, antiviral and antitumor functions. Curr Opin Immunol 2003; 15: 533-543.

26. Heusel JW, Wesselschmidt RL, Shresta S, Russell JH, Ley TJ. Cytotoxic lymphocytes require granzyme $B$ for the rapid induction of DNA fragmentation and apoptosis in allogeneic target cells. Cell 1994; 76: 977-987.
27. Pardo J, Bosque A, Brehm R, Wallich R, Naval J, Mullbacher A et al. Apoptotic pathways are selectively activated by granzyme $A$ and/or granzyme $B$ in CTL-mediated target cell lysis. J Cell Biol 2004; 167: 457-468.

28. Adrain C, Murphy BM, Martin SJ. Molecular ordering of the caspase activation cascade initiated by the cytotoxic T lymphocyte/natural killer (CTL/NK) protease granzyme B. J Biol Chem 2005; 280: 4663-4673.

29. Cullen SP, Adrain C, Luthi AU, Duriez PJ, Martin SJ. Human and murine granzyme B exhibit divergent substrate preferences. J Cell Biol 2007; 176: 435-444.

30. Martin SJ, Amarante-Mendes GP, Shi L, Chuang TH, Casiano CA, O'Brien GA et al. The cytotoxic cell protease granzyme $B$ initiates apoptosis in a cell-free system by proteolytic processing and activation of the ICE/CED-3 family protease, CPP32, via a novel two-step mechanism. EMBO J 1996; 15: 2407-2416.

31. Alimonti JB, Shi L, Baijal PK, Greenberg AH. Granzyme B induces BID-mediated cytochrome c release and mitochondrial permeability transition. J Biol Chem 2001; 276: 6974-6982.

32. Barry M, Heibein JA, Pinkoski MJ, Lee SF, Moyer RW, Green DR et al. Granzyme B shortcircuits the need for caspase 8 activity during granule-mediated cytotoxic T-lymphocyte killing by directly cleaving Bid. Mol Cell Biol 2000; 20: 3781-3794.

33. Sutton VR, Davis JE, Cancilla M, Johnstone RW, Ruefli AA, Sedelies K et al. Initiation of apoptosis by granzyme $B$ requires direct cleavage of bid, but not direct granzyme B-mediated caspase activation. J Exp Med 2000; 192: 1403-1414.

34. Casciola-Rosen L, Garcia-Calvo M, Bull HG, Becker JW, Hines T, Thornberry NA et al. Mouse and human granzyme $B$ have distinct tetrapeptide specificities and abilities to recruit the bid pathway. J Biol Chem 2007; 282: 4545-4552.

35. Kaiserman D, Bird CH, Sun J, Matthews A, Ung K, Whisstock JC et al. The major human and mouse granzymes are structurally and functionally divergent. J Cell Biol 2006; 175 619-630.

36. Thomas DA, Scorrano L, Putcha GV, Korsmeyer SJ, Ley TJ. Granzyme B can cause mitochondrial depolarization and cell death in the absence of BID, BAX, and BAK. Proc Natl Acad Sci USA 2001; 98: 14985-14990.

37. Fan Z, Beresford PJ, Oh DY, Zhang D, Lieberman J. Tumor suppressor NM23-H1 is a granzyme A-activated DNase during CTL-mediated apoptosis, and the nucleosome assembly protein SET is its inhibitor. Cell 2003; 112: 659-672.

38. Chowdhury D, Beresford PJ, Zhu P, Zhang D, Sung JS, Demple B et al. The exonuclease TREX1 is in the SET complex and acts in concert with NM23-H1 to degrade DNA during granzyme A-mediated cell death. Mol Cell 2006; 23: 133-142.

39. Martinvalet D, Zhu P, Lieberman J. Granzyme A induces caspase-independent mitochondrial damage, a required first step for apoptosis. Immunity 2005; 22: 355-370.

40. Zhao $T$, Zhang $H$, Guo $Y$, Fan Z. Granzyme $K$ directly processes bid to release cytochrome $\mathrm{c}$ and endonuclease $\mathrm{G}$ leading to mitochondria-dependent cell death. J Biol Chem 2007; 282: 12104-12111.

41. Zhao $T$, Zhang $H$, Guo $Y$, Zhang $Q$, Hua G, Lu $H$ et al. Granzyme $K$ cleaves the nucleosome assembly protein SET to induce single-stranded DNA nicks of target cells. Cell Death Differ 2007; 14: 489-499.

42. Guo Y, Chen J, Zhao T, Fan Z. Granzyme K degrades the redox/DNA repair enzyme Ape1 to trigger oxidative stress of target cells leading to cytotoxicity. Mol Immunol 2008; 45: 2225-2235.

43. Getachew $Y$, Stout-Delgado H, Miller BC, Thiele DL. Granzyme C supports efficient CTLmediated killing late in primary alloimmune responses. J Immunol 2008; 181: 7810-7817.

44. Johnson H, Scorrano L, Korsmeyer SJ, Ley TJ. Cell death induced by granzyme C. Blood 2003; 101: 3093-3101.

45. Kelly JM, Waterhouse NJ, Cretney E, Browne KA, Ellis S, Trapani JA et al. Granzyme M mediates a novel form of perforin-dependent cell death. J Biol Chem 2004; 279: 22236-22242.

46. Bovenschen N, de Koning PJ, Quadir R, Broekhuizen R, Damen JM, Froelich CJ et al. NK cell protease granzyme $M$ targets alpha-tubulin and disorganizes the microtubule network. J Immunol 2008; 180: 8184-8191.

47. Cullen SP, Luthi AU, Martin SJ. Analysis of apoptosis in cell-free systems. Methods 2008; 44: 273-279.

48. Ostrand-Rosenberg S. Immune surveillance: a balance between protumor and antitumor immunity. Curr Opin Genet Dev 2008; 18: 11-18.

49. Rygaard J, Povlsen CO. The mouse mutant nude does not develop spontaneous tumours. An argument against immunological surveillance. Acta Pathol Microbiol Scand B Microbiol Immunol 1974; 82: 99-106.

50. Stutman O. Tumor development after 3-methylcholanthrene in immunologically deficient athymic-nude mice. Science 1974; 183: 534-536.

51. Stutman O. Immunodepression and malignancy. Adv Cancer Res 1975; 22: 261-422.

52. Shankaran V, Ikeda H, Bruce AT, White JM, Swanson PE, Old LJ et al. IFNgamma and lymphocytes prevent primary tumour development and shape tumour immunogenicity. Nature 2001; 410: 1107-1111.

53. Girardi M, Oppenheim DE, Steele CR, Lewis JM, Glusac E, Filler R et al. Regulation of cutaneous malignancy by gammadelta T cells. Science 2001; 294: 605-609.

54. Smyth MJ, Crowe NY, Godfrey DI. NK cells and NKT cells collaborate in host protection from methylcholanthrene-induced fibrosarcoma. Int Immunol 2001; 13: 459-463.

55. Smyth MJ, Thia KY, Street SE, Cretney E, Trapani JA, Taniguchi M et al. Differential tumor surveillance by natural killer (NK) and NKT cells. J Exp Med 2000; 191: $661-668$. 
56. Davis JE, Smyth MJ, Trapani JA. Granzyme A and B-deficient killer lymphocytes are defective in eliciting DNA fragmentation but retain potent in vivo anti-tumor capacity. Eur $J$ Immunol 2001; 31: 39-47.

57. Mullbacher A, Waring P, Tha Hla R, Tran T, Chin S, Stehle T et al. Granzymes are the essential downstream effector molecules for the control of primary virus infections by cytolytic leukocytes. Proc Natl Acad Sci USA 1999; 96: 13950-13955.

58. Muller U, Sobek V, Balkow S, Holscher C, Mullbacher A, Museteanu C et al. Concerted action of perforin and granzymes is critical for the elimination of Trypanosoma cruzi from mouse tissues, but prevention of early host death is in addition dependent on the FasL/ Fas pathway. Eur J Immunol 2003; 33: 70-78.

59. Riera L, Gariglio M, Valente G, Mullbacher A, Museteanu C, Landolfo S et al. Murine cytomegalovirus replication in salivary glands is controlled by both perforin and granzymes during acute infection. Eur J Immunol 2000; 30: 1350-1355.

60. Smyth MJ, Street SE, Trapani JA. Cutting edge: granzymes $A$ and $B$ are not essential for perforin-mediated tumor rejection. J Immunol 2003; 171: 515-518.

61. Street SE, Trapani JA, MacGregor D, Smyth MJ. Suppression of lymphoma and epithelial malignancies effected by interferon gamma. J Exp Med 2002; 196: 129-134.

62. Kodama T, Takeda K, Shimozato O, Hayakawa Y, Atsuta M, Kobayashi K et al. Perforindependent NK cell cytotoxicity is sufficient for anti-metastatic effect of IL-12. Eur $J$ Immunol 1999; 29: 1390-1396.

63. Smyth MJ, Swann J, Kelly JM, Cretney E, Yokoyama WM, Diefenbach A et al. NKG2D recognition and perforin effector function mediate effective cytokine immunotherapy of cancer. J Exp Med 2004; 200: 1325-1335.

64. Dunn GP, Old LJ, Schreiber RD. The immunobiology of cancer immunosurveillance and immunoediting. Immunity 2004; 21: 137-148.

65. Gorelik L, Flavell RA. Transforming growth factor-beta in T-cell biology. Nat Rev Immunol 2002; 2: 46-53.

66. Thomas DA, Massague J. TGF-beta directly targets cytotoxic T-cell functions during tumor evasion of immune surveillance. Cancer Cell 2005; 8: 369-380.

67. Zou W. Regulatory T cells, tumour immunity and immunotherapy. Nat Rev Immunol 2006 6: 295-307.

68. Cao X, Cai SF, Fehniger TA, Song J, Collins LI, Piwnica-Worms DR et al. Granzyme B and perforin are important for regulatory T-cell-mediated suppression of tumor clearance. Immunity 2007; 27: 635-646.

69. Menasche G, Feldmann J, Fischer A, de Saint Basile G. Primary hemophagocytic syndromes point to a direct link between lymphocyte cytotoxicity and homeostasis Immunol Rev 2005; 203: 165-179.

70. Sharma V, Delgado M, Ganea D. Granzyme B, a new player in activation-induced cell death, is down-regulated by vasoactive intestinal peptide in TH2 but not Th1 effectors. $\mathrm{J}$ Immunol 2006; 176: 97-110.

71. Mateo V, Ménager M, de Saint-Basile G, Stolzenberg MC, Roquelaure B, André N et al. Perforin-dependent apoptosis functionally compensates Fas deficiency in activationinduced cell death of human T lymphocytes. Blood 2007; 110: 4285-4292.

72. Tak PP, Spaeny-Dekking L, Kraan MC, Breedveld FC, Froelich CJ, Hack CE. The levels of soluble granzyme $A$ and $B$ are elevated in plasma and synovial fluid of patients with rheumatoid arthritis (RA). Clin Exp Immunol 1999; 116: 366-370.

73. Bratke K, Bottcher B, Leeder K, Schmidt S, Kupper M, Virchow Jr JC et al. Increase in granzyme B+ lymphocytes and soluble granzyme B in bronchoalveolar lavage of allergen challenged patients with atopic asthma. Clin Exp Immunol 2004; 136: 542-548.

74. Hodge S, Hodge G, Nairn J, Holmes M, Reynolds PN. Increased airway granzyme b and perforin in current and ex-smoking COPD subjects. COPD 2006; 3: 179-187.

75. Mullbacher A, Ebnet K, Blanden RV, Hla RT, Stehle T, Museteanu C et al. Granzyme A is critical for recovery of mice from infection with the natural cytopathic viral pathogen, ectromelia. Proc Natl Acad Sci USA 1996; 93: 5783-5787.

76. Spaeny-Dekking EH, Hanna WL, Wolbink AM, Wever PC, Kummer JA, Swaak AJ et al. Extracellular granzymes $A$ and $B$ in humans: detection of native species during $C T L$ responses in vitro and in vivo. J Immunol 1998; 160: 3610-3616.

77. Hirayasu H, Yoshikawa Y, Tsuzuki S, Fushiki T. A lymphocyte serine protease granzyme A causes detachment of a small-intestinal epithelial cell line (IEC-6). Biosci Biotechnol Biochem 2008; 72: 2294-2302.

78. Irmler M, Hertig S, MacDonald HR, Sadoul R, Becherer JD, Proudfoot A et al. Granzyme A is an interleukin 1 beta-converting enzyme. J Exp Med 1995; 181: 1917-1922.

79. Sower LE, Froelich CJ, Allegretto N, Rose PM, Hanna WD, Klimpel GR. Extracellular activities of human granzyme A. Monocyte activation by granzyme A versus alphathrombin. J Immunol 1996; 156: 2585-2590.

80. Thornberry NA, Bull HG, Calaycay JR, Chapman KT, Howard AD, Kostura MJ et al A novel heterodimeric cysteine protease is required for interleukin-1 beta processing in monocytes. Nature 1992; 356: 768-774.
81. Yu HB, Finlay BB. The caspase-1 inflammasome: a pilot of innate immune responses. Cell Host Microbe 2008; 4: 198-208.

82. van Dommelen SL, Sumaria N, Schreiber RD, Scalzo AA, Smyth MJ, Degli-Esposti MA. Perforin and granzymes have distinct roles in defensive immunity and immunopathology. Immunity 2006; 25: 835-848.

83. Buzza MS, Zamurs L, Sun J, Bird CH, Smith Al, Trapani JA et al. Extracellular matrix remodeling by human granzyme $B$ via cleavage of vitronectin, fibronectin, and laminin. J Biol Chem 2005; 280: 23549-23558.

84. Froelich CJ, Zhang X, Turbov J, Hudig D, Winkler U, Hanna WL. Human granzyme $B$ degrades aggrecan proteoglycan in matrix synthesized by chondrocytes. $\mathrm{J}$ Immunol 1993; 151: 7161-7171.

85. Horton MR, Boodoo S, Powell JD. NF-kappa B activation mediates the cross-talk between extracellular matrix and interferon-gamma (IFN-gamma) leading to enhanced monokine induced by IFN-gamma (MIG) expression in macrophages. J Biol Chem 2002; 277: 43757-43762.

86. Jiang Y, Cheng DW, Crook ED, Singh LP. Transforming growth factor-beta1 regulation of laminin gamma1 and fibronectin expression and survival of mouse mesangial cells. Mol Cell Biochem 2005; 278: 165-175.

87. Noble PW, McKee CM, Cowman M, Shin HS. Hyaluronan fragments activate an NF-kappa B/l-kappa B alpha autoregulatory loop in murine macrophages. J Exp Med 1996; 183: 2373-2378

88. Rucevic M, Fast LD, Jay GD, Trespalcios FM, Sucov A, Siryaporn E et al. Altered levels and molecular forms of granzyme k in plasma from septic patients. Shock 2007; 27: 488-493.

89. Bratke K, Klug A, Julius P, Kuepper M, Lommatzsch M, Sparmann G et al. Granzyme K: a novel mediator in acute airway inflammation. Thorax 2008; 63: 1006-1011.

90. Knickelbein JE, Khanna KM, Yee MB, Baty CJ, Kinchington PR, Hendricks RL. Noncytotoxic lytic granule-mediated CD8+ T cell inhibition of HSV-1 reactivation from neuronal latency. Science 2008; 322: 268-271.

91. Romero P, Zippelius A, Kurth I, Pittet MJ, Touvrey C, lancu EM et al. Four functionally distinct populations of human effector-memory CD8+ T lymphocytes. J Immunol 2007; 178: 4112-4119.

92. Hernandez-Pigeon H, Jean C, Charruyer A, Haure MJ, Titeux M, Tonasso L et al. Human keratinocytes acquire cellular cytotoxicity under UV-B irradiation. Implication of granzyme B and perforin. J Biol Chem 2006; 281: 13525-13532.

93. Matzinger $P$. The danger model: a renewed sense of self. Science 2002; 296: 301-305

94. Osterloh A, Breloer M. Heat shock proteins: linking danger and pathogen recognition. Med Microbiol Immunol 2008; 197: 1-8

95. Luthi AU, Cullen SP, McNeela EA, Duriez PJ, Afonina IS, Sheridan C et al. Suppression of interleukin-33 bioactivity through proteolysis by apoptotic caspases. Immunity 2009; 31: 84-98.

96. Brunner G, Simon MM, Kramer MD. Activation of pro-urokinase by the human T-cellassociated serine proteinase HuTSP-1. FEBS Lett 1990; 260: 141-144.

97. Vanguri $P$, Lee $E$, Henkart $P$, Shin ML. Hydrolysis of myelin basic protein in myelin membranes by granzymes of large granular lymphocytes. J Immunol 1993; 150: 2431-2439.

98. Vettel U, Brunner G, Bar-Shavit R, Vlodavsky I, Kramer MD. Charge-dependen binding of granzyme A (MTSP-1) to basement membranes. Eur J Immunol 1993; 23. 279-282.

99. Suidan HS, Bouvier J, Schaerer E, Stone SR, Monard D, Tschopp J. Granzyme A released upon stimulation of cytotoxic $T$ lymphocytes activates the thrombin receptor on neuronal cells and astrocytes. Proc Natl Acad Sci USA 1994; 91: 8112-8116.

100. Suidan HS, Clemetson KJ, Brown-Luedi M, Niclou SP, Clemetson JM, Tschopp J et al. The serine protease granzyme $A$ does not induce platelet aggregation but inhibits responses triggered by thrombin. Biochem J 1996; 315: 939-945.

101. Froelich CJ, Zhang X, Turbov J, Hudig D, Winkler U, Hana WL. Human granzyme B degrades aggrecan proteoglycan in matrix synthesized by chondrocytes. J Immunol 1993; 151: 7161-7171.

102. Choy JC, Hung VH, Hunter AL, Cheung PK, Motyka B, Goping IS et al. Granzyme B induces smooth muscle cell apoptosis in the absence of perforin: involvement of extracellular matrix degradation. Arterioscler Thromb Vasc Biol 2004; 24: 2245-2250.

103. Gahring L, Carlson NG, Meyer EL, Rogers SW. Granzyme B proteolysis of neuronal glutamate receptor generates autoantigen and is modulated by glycosylation. $\mathrm{J} / \mathrm{mmunol}$ 2001; 166: 1433-1438

104. Mulligan-Kehoe MJ, Drinane MC, Mollmark J, Casciola-Rosen L, Hummers LK, Hall A et al. Antiangiogenic plasma activity in patients with systemic sclerosis. Arthritis Rheum 2007; 56: 3448-3458. 